\title{
Hábitos alimentares aterogênicos de grupos populacionais em área metropoli- tana da região sudeste do Brasil*
}

\author{
Atherogenic alimentary habits of population groups in a metropolitan area of south- \\ eastern Brazil
}

Ignez Salas Martins **, Rosa Nilda Mazzilli**, Rosário Alonso Nieto**, Elaine Donizeti Alvares**, Rosely Oshiro ***, Maria de Fátima Nunes Marucci**, Monica Inês Casajus***

\begin{abstract}
MARTINS, I. S. et al. Hábitos alimentares aterogênicos de grupos populacionais em área metropolitana da região sudeste do Brasil. Rev. Saúde Pública, 28: 349-56, 1994. Em amostra representativa da população de duas áreas de estudo ( 568 indivíduos), Município de Cotia, SP, Brasil, foi realizado inquérito alimentar, baseado na história alimentar do indivíduo. Os objetivos foram: identificar o potencial aterogênico de dietas de diferentes agrupamentos humanos, estratificados em classes sociais e analisar diferenciais de consumo de alguns nutrientes, que conferem aterogenicidade à dieta entre esses agrupamentos. Foram analisados diferenciais de consumo, entre homens e mulheres, segundo classes sociais e tomando-se como referência o percentil $50\left(\mathrm{P}_{50}\right)$ da amostra, dos seguintes constituintes da dieta: energia, proteínas totais, proteínas de origem animal, percentagem de calorias protéicas (P\%), ácidos graxos, gorduras, carboidratos. Seguindo esse critério, foram analisados perfis de dieta em relação às recomendações do National Cholesterol Education Program (NEP) no que diz respeito às calorias fornecidas pelas gorduras (G>30\%), ac. graxos saturados (AGS $>10 \%$ ), carboidratos ( $\mathrm{HC}>60 \%$ ) e colesterol $(>300 \mathrm{mg} / \mathrm{dia})$. Os resultados mostraram que os diferenciais de consumo foram mais pronunciados entre os homens do que entre as mulheres. As classes sociais, entre os homens, que apresentaram maiores percentuais acima do $\mathrm{P}_{50}$ da amostra, no que diz respeito à energia, proteínas totais, gorduras e carboidratos, foram as representadas pelos trabalhadores não qualificados, que se dedicam a trabalhos braçais com alto consumo energético e a dos pequenos proprietários e comerciantes. A classe de maior poder aquisitivo e nível educacional apresentou consumo moderado desses constituintes. $O$ consumo de proteínas de origem animal, acima do $\mathrm{P}_{50}$, entre homens e mulheres, guardou relação direta com o nível socioeconômico da classe . A participação calórica das gorduras $(\mathrm{G} \%)$ e proteínas $(\mathrm{P} \%$ ) foi diretamente proporcional ao poder aquisitivo da classe, ao passo que a dos carboidratos (HC\%) guardou relação inversa. Por outro lado, o consumo de colesterol acima de $300 \mathrm{mg} / \mathrm{dia}$ situou-se nas faixas de 37 a $50 \%$ e de 20 a $32 \%$ para os homens e mulheres, respectivamente. A percentagem de dietas com calorias provenientes das gorduras ( $\mathrm{G} \%$ ) acima de $30 \%$ variou de 25 a $40 \%$, para os homens e de 45 a $50 \%$ para as mulheres. A participação dos ácidos graxos saturados (AGS\%) em proporções maiores ou iguais a 10 foi relativamente baixa para ambos os sexos: de 5 a $17 \%$ para os homens e menos de $10 \%$ para as mulheres. Os percentuais de casos em que a relação ácidos graxos saturados e insaturados (AGS/AGI) guardou valores menores ou iguais a 1, também foi baixa para a população em geral; situou-se entre 7 e $22 \%$ para os homens e em proporções abaixo de $10 \%$, para as mulheres. Concluiu-se que a dieta se apresenta como provável fator de risco de doenças cardiovasculares, dislipidemias, obesidade e hipertensão, para grande parte da população.
\end{abstract}

Descritores: Dieta aterogênica. Classe social. Hábitos alimentares.

\section{Introdução}

O presente trabalho faz parte do projeto "Doenças cardiovasculares ateroscleróticas, dislipidemias,

* Subvencionado pelo CNPq (Conselho Nacional de Desenvolvimento Tecnológico)-Processo $\mathrm{N}^{\circ}$ 410427/89-6 e FAPESP (Fundação de Amparo à Pesquisa do Estado de São Paulo)- Processo No 91/0820-7.

** Departamento de Nutriçāo da Faculdade de Saúde Pública da Unversidade de São Paulo-São Paulo,SP -Brasil hipertensão, obesidade e diabetes melito em população da Área Metroplitana de São Paulo (SP)", cujo objetivo precípuo foi o estabelecimento de uma linha de base para o estudo dessas morbidades e seus fatores de risco.

*** Bolsistas do CNPq no Departamento de Nutrição da Faculdade de Saúde Pública da Universidade de São Paulo - São Paulo, SP - Brasil

Separatas/Reprints : I. S. Martins - Av. Dr. Arnaldo, 715.01246904 - São Paulo, SP - Brasil

Edição subvencionada pela FAPESP. Processo 94/0500-0 
A alimentação pode constituir-se em importante fator de risco de doenças cardiovasculares ateroscleróticas, na medida em que contribui para a etiologia das dislipidemias, obesidade e hipertensão $0^{6,32,34}$. Tem sido constatada estreita relação entre o consumo qualitativo e quantitativo de gorduras e de colesterol com essas morbidades $12,14,15,18,19,20,21,23$.

Portanto, de fundamental importância a identificação de hábitos alimentares, na medida em que a dieta faz parte da etiologia dessas morbidades.

A partir da década de 1960, proliferaram programas de intervenção, principalmente nos países desenvolvidos, onde a mortalidade por doenças cardiovasculares se mostrava bastante expressiva. Foram convocados diferentes comitês de peritos em nutrição, com a responsabilidade de formular recomendações de consumo de colesterol e de perfis de dietas, considerando a contribuição calórica das gorduras e dos ácidos graxos. As recomendações de energia, para esses países, desde então pautaram-se em modelos que consideravam o sedentarismo como problema fundamental dos estilos de vida reconhecidos.

Diversas pesquisas, nesse período, foram voltadas à busca de indicadores de aterogenicidade de dietas a partir de seus conteúdos energéticos, teores de colesterol e dos ácidos graxos saturados e insaturados $5,7,24,31,33$.

Assim, à luz dos conhecimentos atuais, o presente trabalho tem como objetivos: identificar o potencial aterogênico de dietas, de diferentes classes sociais presentes em amostra populacional e analisar diferenciais de consumo de alguns nutrientes que contribuem para a aterogenicidade da dieta.

\section{Material e Método}

A metodologia adotada na pesquisa, que se encontra amplamente descrita em trabalho anterior ${ }^{13}$, contempla o estudo de grupamentos sociais específicos, definidos segundo critérios geográficos e socioeconômicos. Assim, a partir de regiões situadas no centro e nas periferias do Município foram delineadas "áreas de estudo", nas quais foram definidos grupamentos sociais, utilizando-se o conceito de classes, vinculado à idéia de uma estrutura social historicamente determinada, em um modo de produção específico.

Por meio de entrevista, obtiveram-se informações de caráter socioeconômico (ocupação, posição na ocupação, posse de propriedade, número de empregados, escolaridade e renda) a respeito do entrevistado e do chefe de família. A partir desses indicadores, família e indivíduos foram considerados adscritos a classes sociais como burguesia, pequena burguesia tradicional, proletariado e subproletariado, com as seguintes características:

burguesia - formada por proprietários empregado- res, com mais de cinco empregados ou profissionais de nível universitário;

pequena burguesia tradicional - formada por pequenos proprietários, com menos de cinco empregados, comerciantes, com nível médio ou primário de escolaridade e renda mensal maior do que cinco salários mínimos;

proletariado - formada por assalariados com conhecimento de ofício, correspondendo a níveis primário ou médio de escolaridade;

subproletariado - formada por subempregados ou pequenos proprietários, geralmente sem emprego fixo, sem conhecimento de ofício e com rendimentos mensais abaixo de cinco salários mínimos.

$O$ inquérito alimentar centrou-se no levantamento da história alimentar do indivíduo. Foram estimados os consumos dos seguintes nutrientes e constituintes da dieta: energia total, proteínas totais, proteínas de origem animal, carboidratos totais, lipídios totais, ácidos graxos insaturados, ácidos graxos saturados e colesterol.

Para tanto, foi utilizada uma compilação de diversas tabelas de composição de alimentos 3,4,10, 30*. Também, foram calculados os seguintes indicadores de composição da dieta: percentagem de calorias provenientes dos lipídios (G\%), carboidratos (HC\%), ácidos graxos saturados (AGS\%) e relação ácidos graxos saturados/ ácidos graxos insaturados (AGS/ AGI). Para a análise da composição da dieta foram usados como padrões de referência as recomendações do National Cholesterol Education Program (NEP) ${ }^{26}$, que são as seguintes:

lipídios totais (\% de calorias) $\quad<30$

AGS/AGI $<1,0$

ácidos graxos saturados

(\% de calorias)

carboidratos totais

(\% de calorias) $\quad 50-60$

colesterol (mg/dia) $\quad<300$

A fim de se caracterizar diferenciais de consumo entre as classes sociais foram adotados como referência as quantidades correspondentes ao consumo diário do percentil $50 \mathrm{P}_{50}$ dos homens e mulheres da amostra (Tabela1).

Os inquéritos alimentares foram realizados em 1990, em uma amostra representativa das populações ( 568 indivíduos), das "áreas de estudo" 2 e 3 (Tabela 2). Algumas entrevistas foram incompletas tendo sido, portanto, estudados 561 indivíduos.

Para cada classe social, estratificada segundo sexo e idade, foram calculadas as médias aritméticas das

\footnotetext{
* As tabelas elaboradas a partir da compilação de dados encontram-se à disposição no Departamento de Nutrição da Faculdade de Saúde Pública da Universidade de São Paulo, Av. Dr. Arnaldo, 715 - São Paulo, SP - 01246-904.
} 


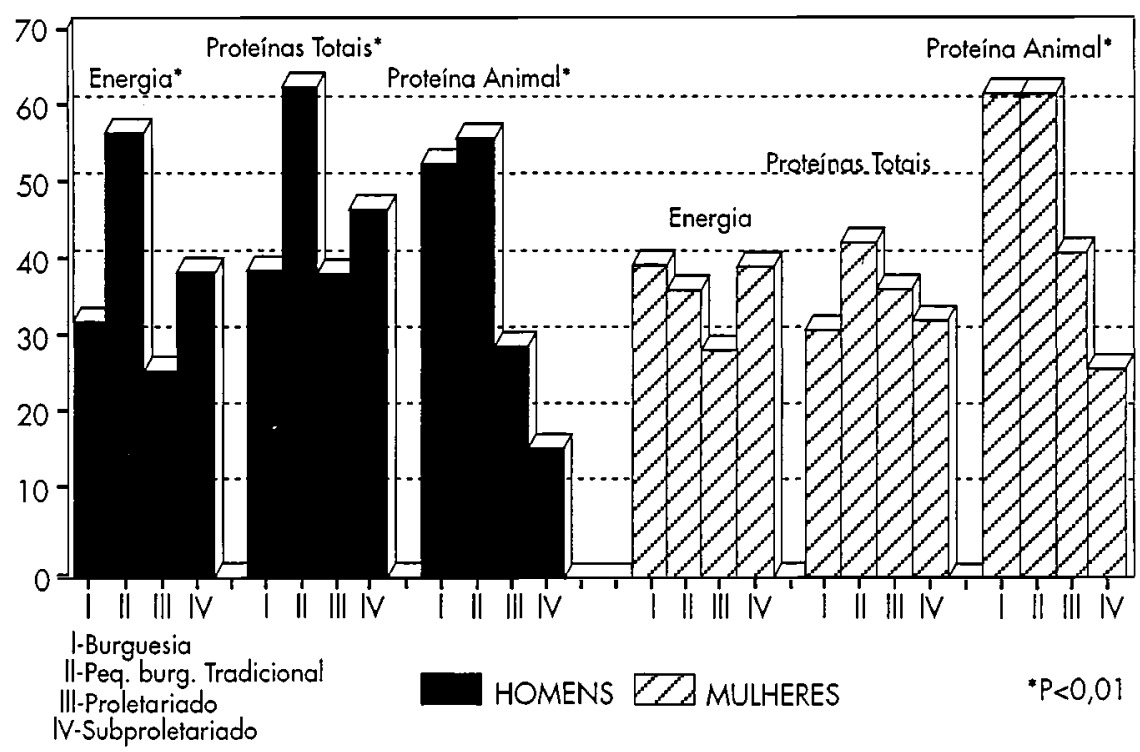

Figura 1: Percentual de consumo de energia e proteínas, segundo classe social e sexo. Municipio de Cotia, 1990.

Tabela 1: Consumo de energia, proteinas, gorduras, ácidos graxos e carboidratos entre homens e mulheres pertencentes ao percentil $50\left(P_{50}\right)$ da amostra. Município de Cotia, 1990.

\begin{tabular}{lcc}
\hline Nutriente & Homens & Mulheres \\
\hline Energia (Kcal) & 2.253 & 1.700 \\
Proteinas Totais $(\mathrm{g})$ & 91,5 & 65,0 \\
Proteína Animal $(\mathrm{g})$ & 42,0 & 30,0 \\
Gorduras $(\mathrm{g})$ & 62,0 & 56,0 \\
Ac.Graxos & & \\
Insaturados $(\mathrm{g})$ & 18,0 & 16,0 \\
Ac. Graxos & & \\
Saturados $(\mathrm{g})$ & 15,0 & 13,0 \\
Carboidratos $(\mathrm{g})$ & 320,0 & 230,0 \\
\hline
\end{tabular}

porcentagens de consumo de energia e nutrientes que se situaram acima do percentil $50\left(\mathrm{P}_{50}\right)$. Calcularam-se as médias aritméticas dos percentuais de consumo de dietas, cuja aterogenicidade, medida pelos indicadores citados, ultrapassaram as recomendações do NEP. A fim de se estabelecerem comparações entre as diferentes classes sociais, esses grupamentos foram ajustados em relação à idade, pelo método direto ${ }^{22}$. Para testar a existência ou não de diferenças estatisticamente significantes entre as classes sociais, padronizadas de acordo com a idade, foram utilizados testes Qui-quadrado.

Tabela 2. Número de quadras, domicílios, domicílios amostrados e indivíduos amostrados nas "áreas de estudo". Município de Cotia, 1990.

\begin{tabular}{ccccc}
$\begin{array}{c}\text { "Área de } \\
\text { Estudo" }\end{array}$ & $\begin{array}{c}\text { № de } \\
\text { Quadras }\end{array}$ & $\begin{array}{c}\text { № de } \\
\text { Domicílios }\end{array}$ & $\begin{array}{c}\text { Domicilios } \\
\text { Amostrados }\end{array}$ & $\begin{array}{c}\text { № de indivíduos } \\
\text { amostrdos }\end{array}$ \\
\hline 2 & 33 & 538 & $130(24,2 \%)$ & 216 \\
3 & 44 & 725 & $170(23,4)$ & 352 \\
\hline Total & 77 & 1.263 & $300(23,7 \%)$ & 568 \\
\hline
\end{tabular}

\section{Resultados e Comentários}

Os consumos de energia e proteínas, de homens e mulheres, referidos como média aritmética da percentagem de indivíduos que apresentaram ingestão acima do correspondente ao $\mathrm{P}_{50}$ da amostra, estão apresentados na Figura 1. No que se refere à energia total da dieta, entre os homens, constata-se maior proporção de consumo entre os pequenos proprietários ou comerciantes , $57 \%$, os proprietários situaram-se em $32 \%$, os empregados assalariados em $26 \%$ e o subempregados ou biscateiros, em $39 \%$.

O consumo de proteínas totais registrou comportamento semelhante ao da energia total: $63 \%$ dos pequenos proprietários ou comerciantes, $47 \%$ dos subempregados, $37 \%$ dos empregados e $38 \%$ dos proprietários ou profissionais de nível universitário, apresentaram consumo acima do $\mathrm{P}_{50}$ da amostra. Por outro lado, a ingestão de proteínas de origem animal guardou relação direta com o nível socioeconômico da classe, como era de se esperar, dado o alto custo dos alimentos de origem animal: $52 \%$ dos proprietários ou profissionais de nível universitário e $56 \%$ dos pequenos proprietários ou comerciantes situaram-se acima do $\mathrm{P}_{50}$, ao passo que os empregados com conhecimento de ofício e os subempregados apresentaram proporções de 29 e $26 \%$, respectivamente.

Todos os diferenciais referidos foram estatisticamente significantes $(\mathrm{p}<0,01)$ quando as classes sociais foram consideradas em conjunto ou comparadas duas a duas.

O consumo observado deixa transparecer que, além da tendência de maior capacidade de aquisição dos alimentos de alto custo pelas classes de maior 


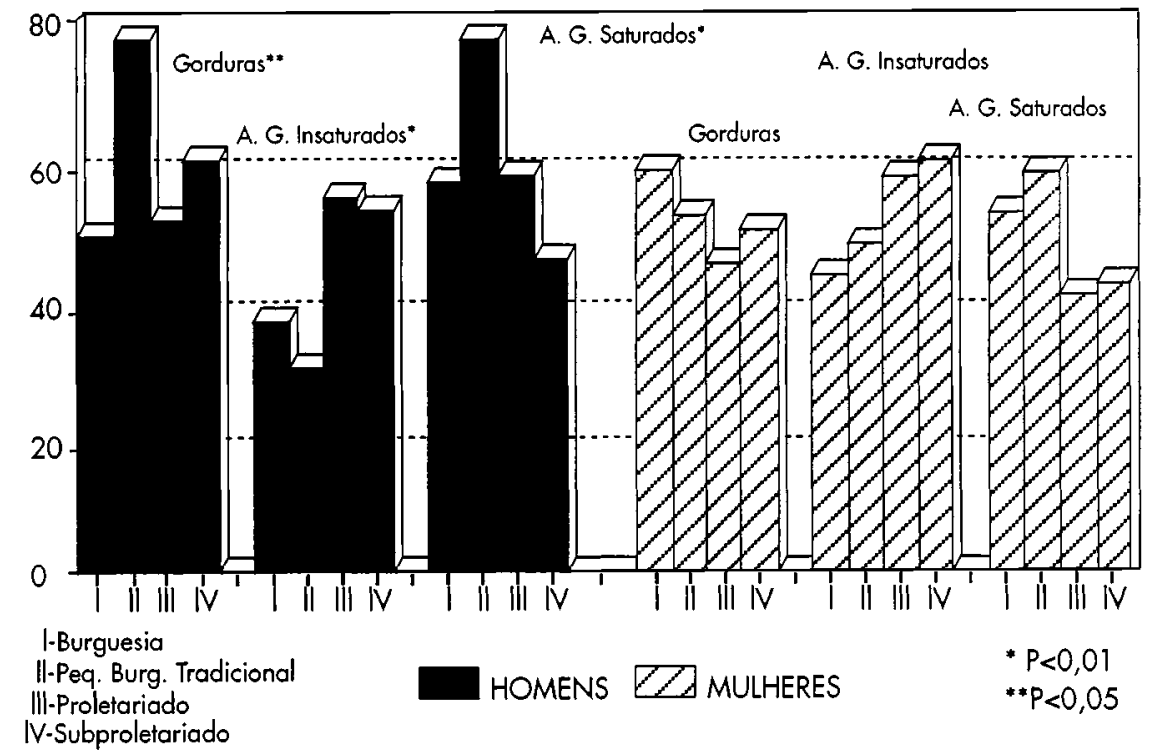

Figura 2. Consumo de gorduras e ácidos graxos acima do (percentil 50), segundo classe social e sexo. Município de Cotia, 1990.

poder aquisitivo, também, fatores relativos à cultura de classe, voltados à valorização do alimento, podem explicar esses resultados. Por exemplo, os pequenos proprietários ou comerciantes apresentam proporções de consumo maiores que o dos proprietários ou profissionais de nível universitário, sugerindo a valorização da mesa farta. A postura mais comedida da classe de maior nível socioeconômico provavelmente esteja vinculada ao melhor nível educacional* de seus componentes, esclarecidos sobre os benefícios e agravos à saúde decorrentes da alimentação.

Por outro lado, o comportamento dos subempregados, que apresentam maior consumo de energia e proteínas totais do que asclasses de maior nível socioeconômico, poderia estar expressando necessidades orgânicas mais intensas desse grupamento, dedicado, geralmente, a trabalhos braçais que exigem maior dispêndio energético. Tem sido apontada a associação positiva entre atividade física e consumo energético ${ }^{1,25}$. Existe, entretanto, diferenças qualitativas entre a proteína das dietas das classes de maior poder aquisitivo com a dos subempregados. Estes apresentam baixo consumo de proteínas de origem animal; possivelmente, a combinação do arroz (cereal) com o feijão (leguminosa), tão arraigada em nossos hábitos alimentares, seja a principal fonte de aminoácidos essenciais dessa população.

No que tange aos diferenciais de consumo de energia e proteínas entre as mulheres, constata-se que não foram estatisticamente significantes, a não ser em relação às proteínas de origem animal $(\mathrm{p}<0,05)$ que mantiveram a mesma tendência observada entre

* A escolaridade foi um dos elementos utilizados na operacionalização de classes sociais. os homens: $61 \%$ da classe dos proprietários ou profissionais de nível universitário e dos pequenos proprietários ou comerciantes e $41 \%$ e $26 \%$ dos empregados e subempregados, respectivamente, apresentaram consumo acima do $\mathrm{P}_{50}$ da amostra (Fig. 1).

Diferenciais de consumo de gorduras e de ácidos graxos insaturados e saturados encontram-se na Figura 2. Nota-se, que entre os homens, o consumo de lipídios conservou a tendência anteriormente observada em relação à energia e proteínas totais, ou seja, os pequenos proprietários ou comerciantes apresentaram maior proporção de consumo, que as demais classes, com niveis estatisticamente significantes. A ingestão de ácidos graxos insaturados parece ser inversamente proporcional ao poder aquisitivo da classe. Entre as mulheres, os diferenciais foram menos pronunciados, sem significância estatística, a não ser em relação ao consumo de ácidos graxos saturados, proporcionalmente maior entre a classe dos pequenos proprietários ou comerciantes.

A proporção de indivíduos que apresentaram consumo de colesterol acima das recomendações do NEP ( $300 \mathrm{mg} / \mathrm{dia}$ ) e de carboidratos acima do $\mathrm{P}_{50}$ da amostra, encontra-se na Figura 3. Entre os homens, cerca de $60 \%$ dos proprietários ou profissionais de nível universitário e dos pequenos proprietários ou comerciantes, situaram-se acima dos níveis recomendados; os empregados e subempregados aprensentaram percentuais de 37 e $39 \%$, respectivamente. Por outro lado, o consumo de carboidratos, evidentemente, foi maior entre os pequenos proprietários ou comerciantes (59\%) e os sub empregados (58\%) como se pode verificar nas figuras anteriores, essas duas classes demonstraram maior tendência de ingestão de dietas mais volumosas, compostas 


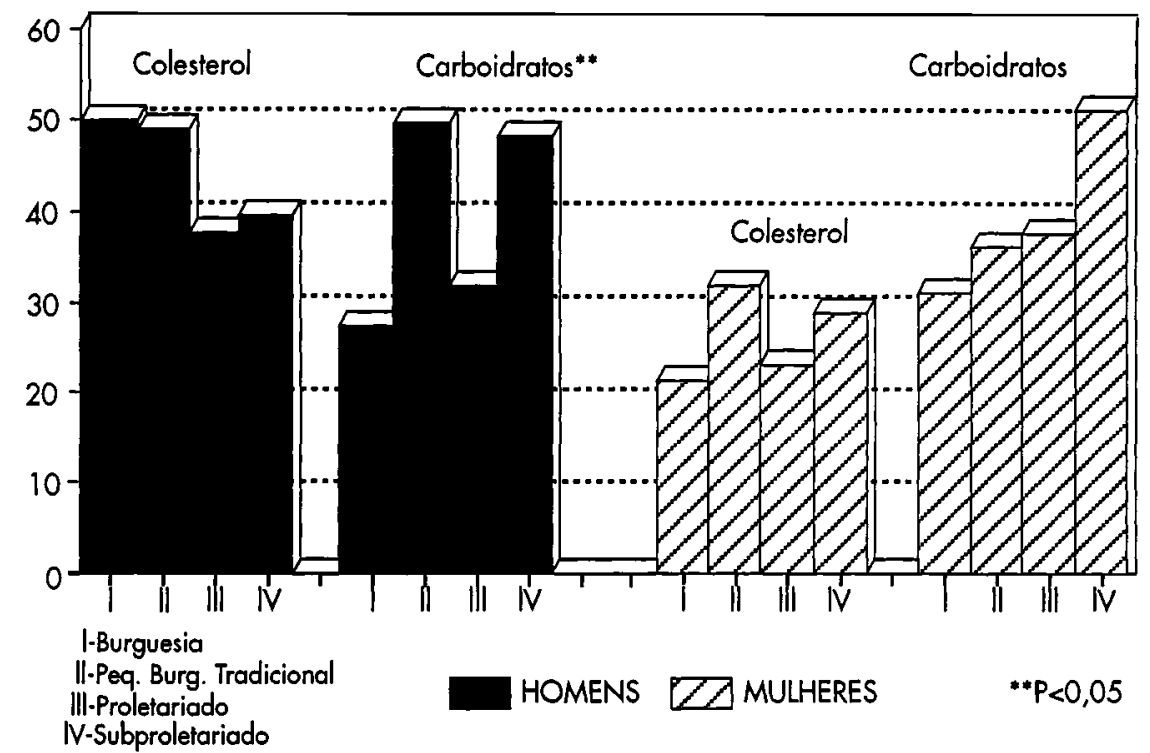

Figura 3. Consumo de colesterol (>300mg) e de carboidratos acima do percentil 50, segundo classe social e sexo. Município de Cotia, 1990.

fundamentalmente de carboidratos.

Entre as mulheres os diferenciais foram menos pronunciados, sem significância estatística.

$\mathrm{Na}$ população geral a proporção de indivíduos com ingestões acima das recomendações variou entre 20 e $60 \%$, constatação relevante do ponto de vista da saúde pública, devido a associação demonstrada entre à ingestão de colesterol e as doenças cardiovasculares ateroscleróticas $8,9,21,29$.

Perfis de dietas, demonstrando percentagens de calorias provenientes de proteínas ( $\mathrm{P} \%)$, carboidratos $(\mathrm{HC} \%)$, gorduras $(\mathrm{G} \%)$, ácidos graxos insaturados
(AGI\%) e ácidos graxos saturados (AGS\%), de homens e mulheres, são apresentados nas Figuras 4 e 5. Constata-se que a concentração de proteínas ( $\mathrm{P} \%)$ é inversamente proporcional ao poder aquisitivo da classe, com diferenciais estatisticamente significantes entre os homens. A proporção de casos em que a concentração de gorduras (G\%) e ácidos graxos saturados (AGS\%) e a relação ac.graxos saturados e ácidos graxos insaturados (AGS/AGI) ultrapassaram as recomendações do NEP tende a ser maior nas classes sociais de nível socioeconômico mais elevados (Figura 5). Entre as mulheres não foram encontra-

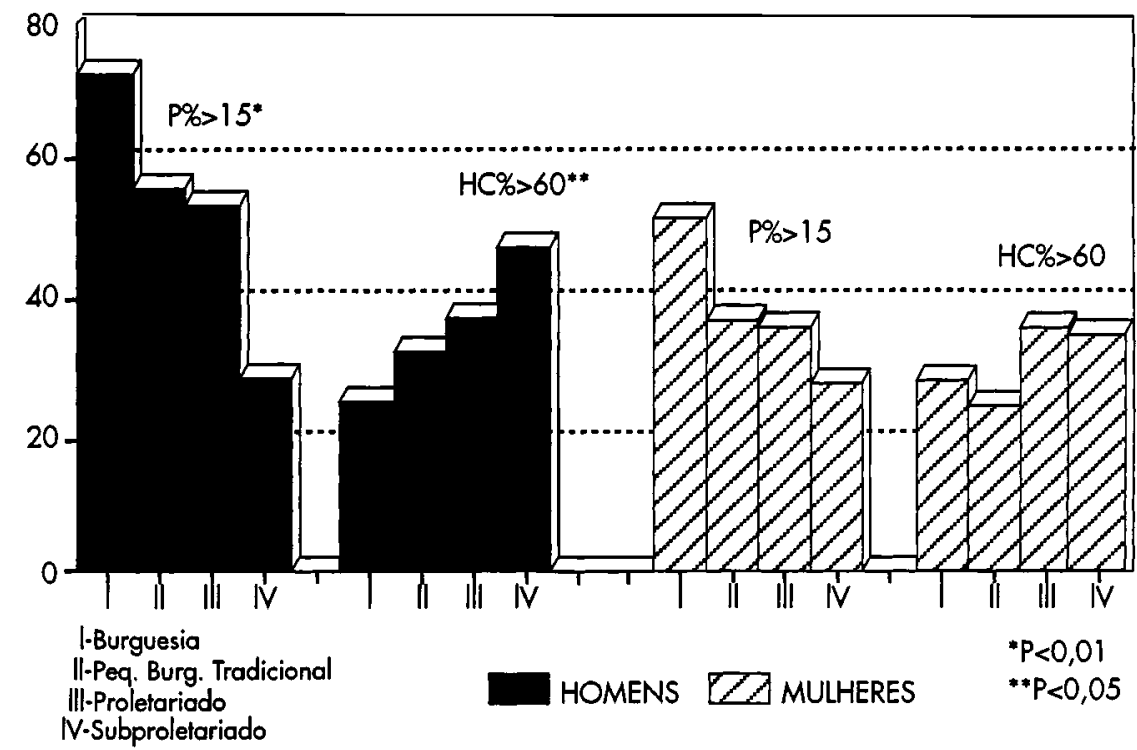

Figura 4. Consumo de calorias fornecidas por proteínas $(>15 \%)$ e carboidratos $(>60 \%)$, segundo classe social e sexo. Município de Cotia, 1990. 


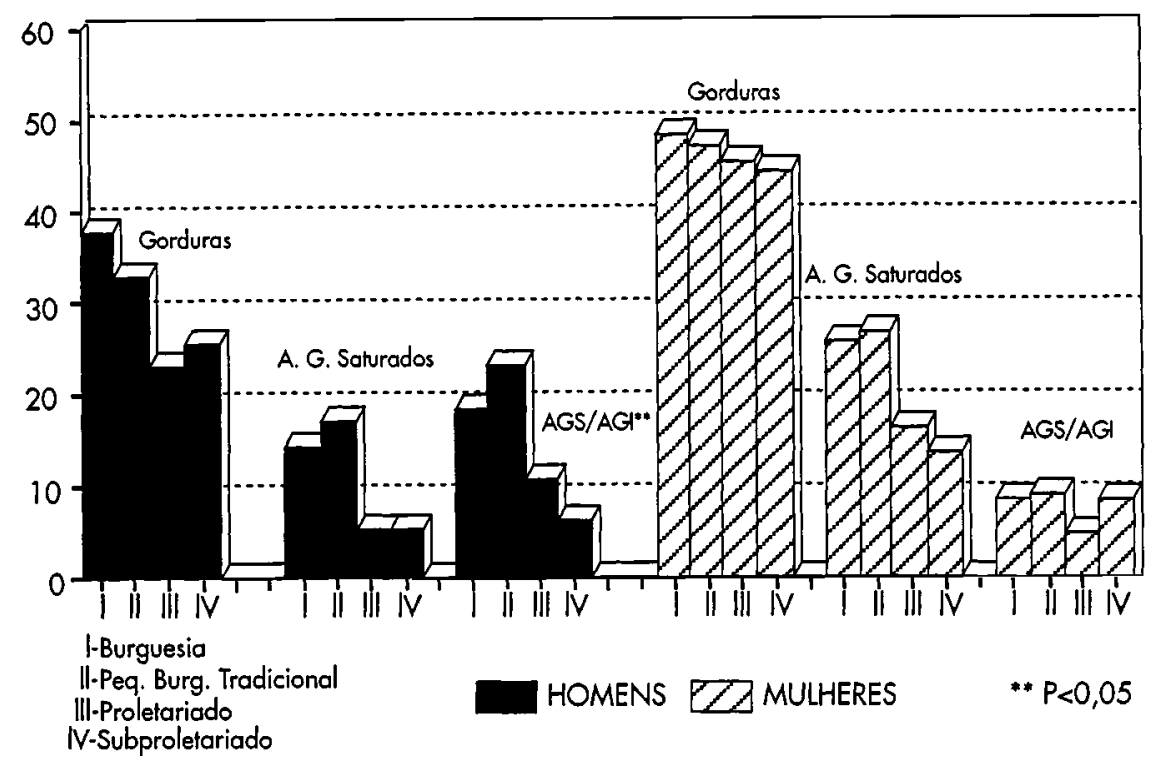

Figura 5. Consumo de gorduras (G>30\%), ácidos graxos saturados (AGS>10\%) e relação $(S />1,0)$, segundo classe socia! e sexo. Município de Cotia, 1990.

dos diferenciais estatisticamente significantes, cabendo ressaltar, os percentuais relativamente altos de consumo de gorduras (G\%) maior do que as recomendações, cuja variação situou-se, aproximadamente, entre 45 e $50 \%$.

Os percentuais de consumo de ácidos graxos saturados e a relação ácidos graxos saturados e insaturados, acima das recomendações, foram relativamente "baixos" quando comparados com resultados encontrados na população norte-americana, referida no Coronary Artery Risk Development in Young Adults Study ${ }^{28}$ e no Second National Health and Nutrition Examination Survey ${ }^{11}$, mostraram que a quase totalidade da população investigada, consumia dietas com níveis de colesterol, ácidos graxos saturados e gorduras acima das recomendações, independentemente de sexo e raça; no segundo estudo, apenas as mulheres brancas, apresentaram médias de consumo de colesterol consideradas adequadas. Sabe-se que, em geral, as populações dos países ricos tendem a consumir mais gorduras do que as dos países em desenvolvimento.

Por outro lado, a qualidade da gordura, importante fator de aterogenicidade das dietas $2,16,17,27$, parece ser adequada, principalmente, nos grupamentos de menor poder aquisitivo, que apresentaram baixo consumo de ácidos graxos saturados. Entretanto, o excessivo consumo de colesterol, aliado a alta densidade energética das dietas encontradas, principalmente na classe dos pequenos proprietários ou comerciantes, geralmente com vida sedentária, possivelmente sejam fatores de risco importantes das morbidades em questão para esse grupamento.

Em síntese, o que transparece com certa rele- vância nos hábitos alimentares da população amostrada, estratificada em classes sociais, são os seguintes pontos:

-entre os homens, os diferenciais entre as classes foram mais evidentes do que entre as mulheres;

- dietas mais volumosas e, portanto, com maior proporção de consumo acima do $\mathrm{P}_{50}$, no que diz respeito a energia, proteínas, carboidratos e lipídios, foram encontradas entre os pequenos proprietários ou comerciantes e entre os subempregados, no que diz respeito à população masculina;

- observou-se relação direta entre o consumo de proteínas de origem animal e o nível socioeconômico, na população amostrada;

-proporção expressiva de homens e mulheres de todas as classes, fundamentalmente os pequenos proprietários ou comerciantes, apresentaram perfis de dieta com considerável potencial aterogênico, expressos pelos indicadores percentagem de calorias fornecidas pelas gorduras da dieta $(\mathrm{G} \%)$ e ingestão de colesterol acima de $300 \mathrm{mg} / \mathrm{dia}$.

Portanto, é possível admitir que os hábitos alimentares apresentem-se como fator de risco de doenças cardiovasculares para grande parte da população, na medida em que devem estar participando, principalmente, na etiologia das dislipidemias, obesidade $\mathrm{e}$ hipertensão.

MARTINS, I. S. et al. [Atherogenic alimentary habits of population groups in a metropolitan area of south-eastern Brazil]. Rev. de Saúde Pública, 28: 349 -56, 1994. This present study is one part of the project "Atherosclerotic cardiovascular diseases, lipemic disorders, hypertension, obesity and diabetes mellitus in a population of the 
metropolitan area of S. Paulo, Brazil" undertaken in Cotia county. An alimentary inquiry based on the alimentary history of the individual was carried out among a subsample of the population (568 individuals). The objectives of the inquiry are the following: a)- the identification of the atherogenic potential of the diets of different human groups, stratified according to social class and b) the analysis of consumption differentials of some nutrients, which confer atherogenicity to the diet, as between social classes. The consumption differentials were analyzed as between men and women, by social class and taking the 50th percentile (P50) of the sample as the standard of reference, with regard to the following dietary constituents: energy, total proteins, proteins of animal origin, percentages of protein calories (P\%), fatty acids, fats (F\%) and carbohydrates $(\mathrm{CH} \%)$. Also, according to this criterion,some diet profiles were analyzed in the light of the recommendations of the National Cholesterol Education Program (NEP) as regards the calorie supplied by fats $(\mathrm{F} \%)$, saturated fatty acids (SFA\%), carbohydrates $(\mathrm{CH} \%)$ and cholesterol $(>300 \mathrm{mg} /$ day). The following were the findings obtained: the consumption differentials were more pronounced among the men. The social class which presented the largest percentages above the P50 of the sample, with regard to energy, total proteins, fats and carbohydrates, were the non-specialized workers, i.e. the manual laborers who have a high expendure of energy, and that of small property owners and shop-keepers who lead a sedentary life. The class of the greatest acquisitive power and highest educational level presented a moderate consumption of these constituents. On the other hand, the consumption of the proteins of animal origin, above the P50, among men and women, maintained a direct relationship with socioeconomic level. The proportion of calories coming from fats (F\%) and protein (P\%) was directly proportional to the acquisitive power of the class, while that of carbohydrates $(\mathrm{CH} \%)$ presented an inverse relationship. On the other hand, the consumption of cholesterol in excess of $300 \mathrm{mg} /$ day was found to between 37 and $50 \%$ and 20 and $32 \%$ for men and women, respectively. The percentage of diets with more than $30 \%$ of calories coming from fats $(\mathrm{F} \%)$ varied from 25 to $40 \%$ for men and 45 to $50 \%$ for women. The participation of the saturated fatty acids(SFA\%) in proportions greater or equal to 10 was relatively low for both sexes: being of 5 to $17 \%$ for the men and of less than $10 \%$ for the women. The percentages of cases in the relationship saturated to unsaturated fatty acids (SFA/UFA) maintaining values less than $1 \%$ was also low for the population in general, being of 7 and $22 \%$ for the men and less than $10 \%$ for the women. It is concluded that diet probably is an important risk factor in cardiovascular diseases, lipemic disorders, obesity and hypertension, for a large part of the population, mainly for the small property owners and shop-keepers, is viable.

\section{Referências Bibliográficas}

1. BLOCK,G. et al. Calories, fat and cholesterol: intake patterns in the US population by race, sex and age. Am.J.Public Health, 78:1150-5,1988.

2. CURB, J.D. \& MARCUS, B.E. Body fat and obesity in Japanese Americans. Am. J. Clin. Nutr., 53:1552S-5S, 1991.
3. FRANCO,G. Tabela de composição dos alimentos. $5^{\mathrm{a}}$ ed. Rio de Janeiro, Livraria Ateneu, 1982.

4. FUNDAÇĀO IBGE. Tabela de composiçāo dos alimentos. Rio de Janeiro, 1977. ( Estudo Nacional da Despesa Familiar,3: publicações especiais, $t 1$ ).

5. HEGSTED, D.M. et al. Quantitative effects of dietary fat on serum cholesterol in man. Am. J. Clin. Nutr., 17:281-95, 1965.

6. IACONO,J.M. et al. Dietary polyunsaturated fat and hypertension. Ann. Med., 21:251-4,1989.

7. KEYS,A. et al. Prediction of serum-cholesterol responses of man to change in fats in the diets. Lancet, 2:959-66, 1957.

8. KEYS,A. et al. The diet and 15-year death rate in The Seven Countries Study. Am. J. Epidemiol., 124:903-15,1986.

9. KUSKE,T.T. \& FELDMAN,E.B. Hyperlipoproteinemie, atherosclerosis risk and dietary management. Arch. Intern. Med., 147:357-60, 1987.

10. LEUNG,W.T.W. \& FLORES,M. Tabla de composición de alimentos para uso en América Latina. Guatemala, INCAP/ ICNND, 1971.

11. LINN, S. et al. Serum total cholesterol:HDL cholesterol ratios in a USA white and black adults by selected demographic and socioeconomic variables (HANES II). Am. J. Public Health, 81:1036-43, 1991.

12. LUNKED, E.K. et al. Dietary fat intake and plasma lipid levels in adolescents. Eur.J.Clin.Nutr., 46:857-64, 1992.

13. MARTINS,I.S. et al. Doenças cardiovasculares ateroscleróticas, dislipidemias, hipertensão, obesidade e diabetes melito, em população da área metropolitana da região sudeste do Brasil,(SP): 1 metodologia da pesquisa. Rev. Saúde Píblica., 27:250-61, 1993.

14. MATTSON,F.H. et al. Effect of dietary cholesterol in serum cholesterol in man. Am. J. Clin. Nutr., 25:589-90, 1979.

15. MATTSON,F.H. \& GRUNDY,S.M. Comparison of effects of dietary saturated and monounsaturated fats on plasma lipids and lipoproteins in man. J.Lipid Res., 26:194-202, 1985.

16. MAZIER, P.M.J. \& JONES, J.H. Dietary fat quality and circulating cholesterol levels in humans: a rewiew of actions and mechanisms Prog. Food Nutr. Sci.,15:21-41, 1991.

17. MORTENSEN, A. et al. The influence of dietary olive oil and margarine on aortic cholesterol accumulation in cholesterolfed rabbits maintened at similar plasma cholesterol level. Atherosclerosis, 96: 159-70, 1992.

18. NEUMAN,M.P. et al. Evaluation of the high density lipoprotein cholesterol protective effect against atherogenisis in rabbits fed cholesterol supplemented diets. Medicina, Buenos Aires, 50:343-50, 1990.

19. O'DEA, K. et al. Cholesterol-lowering effects of a low-fat diet containing lean beef is reversed by addition of beef fat. $\mathrm{Am}$. J. Clin. Nutr., 52: 491-4,1990.

20. PYORÄLÄ, K. Dietary cholesterol in relation to plasma cholesterol and coronary heart disease. Am. J. Clin. Nutr., 45:1176-84,1987.

21. QUIVERS, E.S. et al. The effects of diet on serum cholesterol in children. Ann. N Y Acad. Sci., (625):133-4, 1991.

22. SANTOS, J.L. Principais técnicas de análise e projeção. In: Santos, J.L. et al. org. Dinâmica de população: teoria, métodos e técnicas São Paulo, T.A. Queiróz, 1980. p.102.

23. SEIM,H.C. \& HOLTMEIER,K.B. Effects of a six-week, lowfat diet on serum cholesterol, body weight, and body measurements. Farm.Pract. Res. J., 12:411-9, 1992.

24. SMITH,L.B. et al. Dietary and non-dietary predictors of serum total and HDL-cholesterol in men and women: results from the Scottish Health Study. Int. J. Epidemiol., 20:95-109, 1991.

25. SOPKO,G. et al. Dietary measures of physical activity. Am.J.Epidemiol., 120:900-11,1984.

26. U.S. DEPARTMENT OF HEALTH AND HUMAN 
SERVICES. Public Health Services. National Institute of Health. National Cholesterol Education Program.Detection, evaluation, and treatment of high blood cholesterol in adults: report. Bethesda, MD, 1989.

27. VEGA, G.L. et al. Influence of polyunsaturated fats on composition of plasma lipoproteins and apolipoproteins. $J$. Lipid Res., 26:194-202, 1985.

28. VON HORN, L.V. et al. Diet, body size and plasma lipids lipoproteins in young adults: differences by race and sex. The Coronary Artery Risk Development in Young Adults Study (CARDIA). Epidemiology, 133: 9-23, 1991.

29. YARON, N. \& KARNI, A. The cholesterol/saturated fat index of the food supply and nutrient intake in an Israeli community compared with general population. J.Am. Diet. Assoc., 89:804-6,1989.

30. WATT,K.B. \& MERRILL,A.L. Composition offoods. Ed, rev. Washington, DC, Department of Agriculture, 1963. (Agriculture Handbook, 8).

31. WHYTE, H.M. \& HAVENSTEIN, N. A perspective view of dieting to lower to blood cholesterol. Am.J.Clin.Nutr., 29:784-90,1979.

32. WILLIAMS, P.T. et al. Assotiations of dietary fat, regional adiposity, and blood pressure man.JAMA, 257:3251-6,1987.

33. ZILVERSMIT, D.B. Cholesterol index of food. J.Am. Diet. Assoc., 74: 562-5,1979.

34. ZIMMET, Z. P. Obesity, hypertension, carbohydrate disorders and the risk of chronic diseases: is there any epidemiological evidence for integrated prevention programmes? Med. $J$. Aust., 145: 256-62,1986.

Recebido para publicaçāo em 7.12.1993

Reapresentado em 10.6.1994 Aprovado para publicação em 18.7.1994 